\title{
Selection of Jatropha full-sib families based on genotypic adaptability and stability via mixed models
}

\author{
E.V. Rodrigues ${ }^{1}$, P.E. Teodoro ${ }^{2}$, L.A. Peixoto ${ }^{2}$, L.A. Silva ${ }^{2}$, B.G. Laviola ${ }^{1}$ \\ and L.L. Bhering ${ }^{2}$ \\ ${ }^{1}$ Embrapa Agroenergia, Parque Estação Biológica, Brasília, DF, Brasil \\ ${ }^{2}$ Universidade Federal de Viçosa, Campus Universitário, Viçosa, MG, Brasil \\ Corresponding author: L.L. Bhering \\ E-mail: leonardo.bhering@ufv.br \\ Genet. Mol. Res. 16 (3): gmr16039722 \\ Received May 15, 2017 \\ Accepted July 4, 2017 \\ Published July 28, 2017 \\ DOI http://dx.doi.org/10.4238/gmr16039722 \\ Copyright (C) 2017 The Authors. This is an open-access article distributed under the terms of \\ the Creative Commons Attribution ShareAlike (CC BY-SA) 4.0 License.
}

\begin{abstract}
The objectives of this study were to estimate the genetic parameters for Jatropha full-sib families and to select superior genotypes based on grain yield, adaptability, and stability simultaneously to be used for cloning and crossings. Grain yield was evaluated in thirteen full-sib families in a randomized block design for 5 years. The harmonic mean of the relative performance of genotypic values and reaction norm were performed to estimate the adaptability and stability, and sequentially the 30 superior individual plants were selected based on the predicted additive genotypic value for the last crop season. Families 4, 8, and 9 may be used to several regions of Brazil since they have high genotypic adaptability and stability. Individuals belonging to families $9,8,2,1,6$, and 5 should be used for cloning or crossing to obtain the next-generation individuals, and consequently to continue the Jatropha breeding.
\end{abstract}

Key words: Jatropha curcas; REML; BLUP; HMRPGV; Jatropha breeding 


\section{INTRODUCTION}

Jatropha (Jatropha curcas L.) has a huge importance due to its multiple uses (Laviola et al., 2013), such as a fence, phytoremediation, and medicinal use (Sharma et al., 2012). Moreover, Jatropha has become an interesting crop to biofuel production since it has a high seed oil content (Silva Junqueira et al., 2016; Montes and Melchinger, 2016; Peixoto et al., 2016).

Jatropha is spread out in almost all Brazilian regions, and it makes the genotype $\mathrm{x}$ environment interaction important in the selection process. Besides that, Jatropha has an enormous energetic potential, although this species still is in a domestication process in Brazil, which points out the importance of to choose specific selection strategies to develop new cultivars. Moreover, Jatropha is a perennial species that breeders spend a lot of time and resources to evaluate the selective cycles, which it one of the most challenge to turn this culture more sustainable.

Indeed, the application of accurate selection methods is essential to maximize the selection gain. Thus, one of the most important issues in the Jatropha breeding is to identify genotypes with high grain yield, good production stability, and high adaptability for several environments, simultaneously. Studies that consider all of these steps can be performed using mixed model concepts by harmonic mean to the relative performance of genotypic values (HMRPGV) method.

The HMRPGV method was proposed by Resende (2002) and has several advantages such as: the selection of genotypes based on three attributes mentioned above simultaneously, the consideration of genotypic effect as random, the consideration of correlated errors within local or years as well as the stability and adaptability to select individual within progenies, the output is genotypic values $(\mathrm{GV})$ penalized by the instability, and the results are in the same unit of the evaluated trait (Resende et al., 2014).

This method has been applied for several species such as eucalyptus (Silva et al., 2013), cotton (Farias et al., 2016), rubber tree (Silva et al., 2014), and strawberry (Costa et al., 2015). However, few types of research have reported the use of this method in Jatropha breeding (Borges et al., 2014). Therefore, the objectives of this study were to estimate genetic parameters based on Jatropha full-sib families performance and to select superior genotypes for grain yield, adaptability, and stability simultaneously.

\section{MATERIAL AND METHODS}

\section{Experimental design}

The experiment was carried out in the experimental area of Embrapa Cerrado from

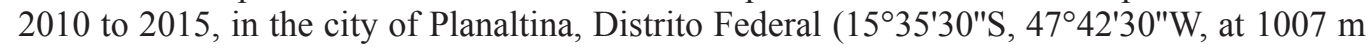
asl). The climate is tropical with dry winter and rainy summer (Aw), according to the Köppen classification, with average annual temperature of $21^{\circ} \mathrm{C}$, relative humidity of $68 \%$, and average rainfall of $1100 \mathrm{~mm} /$ year. Management practices were based on Bahadur et al. (2012).

Thirteen full-sib families were obtained from the crossings between four accessions selected from the Germplasm Bank with the following characteristics: low-height(CNPAE-107), high grain yield (CNPAE-190), the absence of toxicity in the grains (CNPAE-170), and resistance to powdery mildew (CNPAE-259) according to Table 1. A randomized block design with five replications and three plants per plot spaced $4 \times 2 \mathrm{~m}$ between rows was used. After

Genetics and Molecular Research 16 (3): gmr16039722 
crosses, the seeds were germinated in plastic tubes of $500 \mathrm{~mL}$ filled with commercial substrate. Subsequently, the seedlings were transplanted to pit $40 \times 40 \times 40 \mathrm{~cm}$, that was filled with soil, 5 $\mathrm{L}$ bovine manure and $500 \mathrm{~g}$ superphosphate. In the first year of cultivation, three topdressings with $80 \mathrm{~g} /$ plant fertilizer 20-00-20 were performed. Grain yield (g/plant) was evaluated in five crop seasons, corresponding to the second, third, fourth, fifth, and sixth year after planting.

Table 1. Genealogy of the 13 full-sib families evaluated.
\begin{tabular}{l|c|c}
\hline Family & Male genitor & Female genitor \\
\hline 1 & 107 & 107 \\
\hline 2 & 107 & 190 \\
\hline 3 & 107 & 259 \\
\hline 4 & 170 & 107 \\
\hline 5 & 170 & 170 \\
\hline 6 & 170 & 190 \\
\hline 7 & 170 & 259 \\
\hline 9 & 190 & 107 \\
\hline 10 & 190 & 190 \\
\hline 11 & 190 & 259 \\
\hline 12 & 259 & 107 \\
\hline 13 & 259 & 190 \\
\hline
\end{tabular}

\section{Statistical analysis}

REML (restricted maximum likelihood) method was used for estimating variance components, while the prediction of GV was performed using BLUP (best linear unbiased prediction). Initially, the parameters and GV were estimated for each crop season according to the following model:

$$
y=X m+Z a+W p+T f+Q i+R s+e \quad \text { (Equation 1) }
$$

where $y$ is the phenotypic value vector; $m$ is the crop season-block combination effect vector plus the overall mean assigned as fixed; $a$ is the individual additive genotypic effect vector assigned as random; $p$ is the plot effect vector assigned as random; $f$ is the dominance effect vector for full-sib families assigned as random; $i$ is the vector of the effect of family $\mathrm{x}$ crop season interaction assigned as random; $s$ is the permanent effect vector assigned as random; $e$ is the random error vector. $\mathrm{X}, \mathrm{Z}, \mathrm{W}, \mathrm{T}, \mathrm{O}$, and $\mathrm{R}$ represent the incidence matrices for fixed effects, additive genotypic effects, plot effects, dominance effects, family x crop season interaction effects, and permanent effects, respectively.

By using this model, empirical BLUP predictors (eBLUP or REML/BLUP) of the GV without interaction effects was obtained, given by $\hat{\mu}+\hat{g}_{i}$, where $\hat{\mu}$ is the mean of all crop season and $\hat{g}_{i}$ is the genotypic effect of full-sib families without family x crop season interaction. For each season j, GV was predicted by:

$$
\hat{\mu}_{j}+\hat{g}_{i}+(\hat{g} e)_{i j}
$$

where $\hat{\mu}_{j}$ is the mean of the season $\mathrm{j}, \hat{g}_{i}$ is the genotypic effect of full-sib family $\mathrm{i}$ on the crop season $\mathrm{j}$, and $(\hat{g} e)_{i j}$ is the family $\mathrm{x}$ crop season interaction. 
The prediction of GV for each full-sib family that capitalizes the mean interaction in different crop seasons was given by $\hat{\mu}_{j}+\hat{g}_{i}+\hat{g} e_{m}$ and was calculated by:

$$
\mathrm{GV}=\hat{\mu}+\frac{\left(\frac{\hat{\sigma}_{\mathrm{g}}^{2}+\hat{\sigma}_{\mathrm{c}}^{2}}{\mathrm{n}}\right)}{\hat{\sigma}_{\mathrm{g}}^{2}} \hat{\mathrm{g}}_{i}
$$

where $\hat{\mu}$ is the overall mean of all environments; $\mathrm{n}$ is the number of crop seasons; and $\hat{g}_{i}$ is the genotypic effect of full-sib family $i$.

The harmonic mean of the GV (HMGV) for the stability of each full-sib family was obtained by the equation:

$$
\mathrm{HMGH}_{\mathrm{i}}=\frac{\mathrm{n}}{\sum_{\mathrm{j}=1}^{\mathrm{n}} \frac{1}{V g_{\mathrm{ij}}}}
$$

where $\mathrm{n}$ is the number of crop seasons $(\mathrm{n}=5)$ where the genotype $\mathrm{i}$ was evaluated; $V g_{i j}$ is the genotypic value of the family $i$ on the crop season $j$, expressed by the ratio of the mean in this crop season. The values of the relative performance of the GV (RPGV) for adaptability were obtained according to the expression:

$$
R P G V_{i}=\frac{1}{n} \frac{\sum_{j=1}^{n} V g_{i j}}{M_{j}}
$$

where $M_{j}$ is the mean of the yield grain in the crop season $j$.

Joint selection of full-sib families, simultaneously considering yield grain, stability and adaptability, was given by the parameter HMRPGV according to the equation below:

$$
\operatorname{HMRPGV}_{i}=\frac{\mathrm{n}}{\sum_{\mathrm{j}=1}^{\mathrm{n}} \frac{1}{\mathrm{PRVg}_{\mathrm{ij}}}}
$$

Subsequently, linear equations of reaction norms of GV depending on the environmental gradient $(\Delta \mathrm{e})$ were estimated for each full-sib family, defined by:

$$
\Delta \mathrm{e}=\frac{\sum_{\mathrm{j}} \mathrm{Y}_{\mathrm{j}}}{\mathrm{g}}-\overline{\mathrm{Y}}
$$

Genetics and Molecular Research 16 (3): gmr16039722 
where $\sum Y_{j}$ is the total grain yield in the crop season $\mathrm{j} ; \mathrm{g}$ is the number of families; $\overline{\mathrm{Y}}$ is the general phenotypic mean over the crop seasons according to Finlay and Wilkinson (1963).

Finally, the selection of the 30 superior individual plants was performed based on the predicted additive genotypic value for the last crop season. Subsequently, the selection gain and the effective size were calculated for these plants (Resende et al., 2014). All analyses were performed with R (R Core Team, 2015) and the Selegen software (Resende, 2016).

\section{RESULTS AND DISCUSSION}

\section{Estimation of genetic parameters}

The estimation of genotypic variance between Jatropha full-sib families was greater than the estimate of environment variance, although it was much lower than the estimate of family $\mathrm{x}$ crop season interaction variance, and consequently the individual heritability had a low magnitude (Table 2). The individual heritability estimated in this study was lower than the estimates of this parameter in other studies (Laviola et al., 2010; Bhering et al., 2013; Laviola et al., 2013). However, the individual heritability reported in other articles was estimated based on one season, i.e., without family $\mathrm{x}$ crop season interaction. As the grain yield is a polygenic trait highly influenced by the environment and Jatropha is a perennial crop, which selection cycle takes a long time, the estimate of individual heritability calculated considering the family $\mathrm{x}$ crop season interaction is more accurate and may direct the breeders to choose the best selection strategy for this culture.

Table 2. Estimates of genetic parameters based on grain yield evaluation in 13 Jatropha full-sib families over five season crops.

\begin{tabular}{l|c}
\hline Parameter & Estimate \\
\hline Genotypic variance between full-sib families & $12,502.92$ \\
\hline Environmental variance between plots & $12,085.88$ \\
\hline Family x crop season interaction variance & $40,953.75$ \\
\hline Permanent effect variance & 200.12 \\
\hline Residual variance & $105,701.75$ \\
\hline Individual phenotypic variance & $171,444.42$ \\
\hline Individual heritability & 0.07 \\
\hline Coefficient of determination of plot effects & 0.07 \\
\hline Coefficient of determination of family x crop season interaction effects & 0.24 \\
\hline Coefficient of determination of permanent effects & 0.01 \\
\hline Individual repeatability & 0.14 \\
\hline Genetic correlation among crop seasons & 0.23 \\
\hline
\end{tabular}

The coefficient of determination of the family $\mathrm{x}$ crop season effects revealed that approximately $24 \%$ of the individual phenotypic variance was explained by the family $\mathrm{x}$ crop season interaction variance. This finding indicates that it is suitable to perform adaptability and stability analysis to select superior full-sib families for grain yield. On the other hand, the coefficient of determination of the permanent effects was closed to zero $(0.01)$, which indicates that the environmental variance across years can be unvalued for grain yield. The experimental precision was accessed by the estimate of the coefficient of determination of plot effects (0.07), which indicates low magnitude for this parameter, and consequently, there was no environment heterogeneity between plot within blocks (Resende, 2002).

Genetics and Molecular Research 16 (3): gmr16039722 
The individual repeatability is a parameter that allows evaluating how many measures are needed to select superior genotypes with high accuracy. The evaluation of measures over the years is essential to characterize the productive behavior in perennial crops, such as Jatropha, which has a long, productive cycle and the traits are expressed in different ways over the years (Resende, 2002). The individual repeatability obtained in this study $(0.14)$ was lesser than the repeatability reported by Laviola et al. (2013), which found 0.37 for yield grain evaluated for four crop seasons. These results may be explained by the low genotypic correlation between crop seasons $(0.23)$ observed in this research, which demonstrates changes in the family rank over the years.

\section{Genotypic adaptability and stability of full-sib families}

Predicted GV for each Jatropha full-sib family for yield grain ranged over crop seasons (Table 3). For instance, family 7 was the most productive in the first crop season. Meanwhile, it had low grain yield beyond the third crop season. This indicates that the family $\mathrm{x}$ crop season interaction in a complex way was significant, and consequently, it is needed to select families with high adaptability.

Table 3. Estimates of genotypic values for grain yield (g/plant) evaluated in 13 full-sib families in five crop seasons and the crop season average predicted by BLUP analysis.

\begin{tabular}{l|c|c|c|c|c|c}
\hline \multirow{2}{*}{ Family } & Crop season 1 & Crop season 2 & Crop season 3 & Crop season 4 & Crop season 5 & Average \\
\cline { 2 - 7 } & $\hat{\mu}_{1}+\hat{\mathrm{g}}+\hat{\mathrm{g} e}$ & $\hat{\mu}_{1}+\hat{\mathrm{g}}+\hat{\mathrm{g} e}$ & $\hat{\mu}_{1}+\hat{\mathrm{g}}+\hat{\mathrm{g} e}$ & $\hat{\mu}_{1}+\hat{\mathrm{g}}+\hat{\mathrm{g} e}$ & $\hat{\mu}_{1}+\hat{\mathrm{g}}+\hat{\mathrm{g} e}$ & $\hat{\mu}+\hat{\mathrm{g}}+\hat{\mathrm{g} e m}$ \\
\hline 1 & 33.95 & 371.54 & 568.13 & 1417.66 & 1074.42 & 610.68 \\
\hline 2 & 26.39 & 325.53 & 528.18 & 1512.62 & 1088.41 & 613.74 \\
\hline 3 & 38.75 & 250.60 & 436.25 & 1263.13 & 1047.14 & 397.91 \\
\hline 4 & 62.59 & 353.96 & 404.74 & 1665.82 & 1297.21 & 707.95 \\
\hline 5 & 30.16 & 301.27 & 360.10 & 1205.30 & 1118.18 & 406.93 \\
\hline 6 & 56.13 & 401.20 & 328.94 & 1452.65 & 1138.26 & 600.08 \\
\hline 7 & 65.37 & 281.55 & 315.93 & 1104.01 & 1061.35 & 367.45 \\
\hline 8 & 36.11 & 338.91 & 588.99 & 1573.65 & 1166.70 & 689.35 \\
\hline 9 & 49.41 & 439.99 & 501.26 & 1477.92 & 1220.99 & 675.41 \\
\hline 10 & 41.44 & 237.54 & 343.38 & 1155.49 & 1188.39 & 414.65 \\
\hline 11 & 28.27 & 225.79 & 379.69 & 1332.18 & 1274.71 & 525.04 \\
\hline 13 & 31.88 & 213.37 & 303.52 & 1046.83 & 1151.52 & 333.68 \\
\hline
\end{tabular}

The parameter $\hat{\mu}+\hat{g}+\hat{g e m}$ refers to the average genotypic value for each crop season, and it capitalizes the average interaction for all crops (Resende, 2002). The superior full-sib families based on the average of the GV over crop seasons were 4,8 , and 9 , which also were superior in the third and fifth seasons (Table 3). Jatropha is considered a species that has not domesticated in Brazil yet, which the economic viability depends on the identification of genotypes that maintain their grain yield high over crop seasons (Spinelli et al., 2015). Therefore, the selection of superior full-sib families that may be used in the vegetative propagation can contribute to increasing the commercial success of this culture.

Few studies have demonstrated the small genetic variability among Brazilian Jatropha genotypes (Rosado et al., 2010; Bhering et al., 2015). Thus, another strategy that can be used to increase the genetic variability is crossing among superior genotypes in an intrapopulation recurrent selection program, which allows exploiting a major proportion of the additive genetic variability available (Resende, 2002).

The full-sib families 4,8 , and 9 were also the three superior families according to

Genetics and Molecular Research 16 (3): gmr16039722 
MHPRGV method (Table 4), i.e., these families have high grain yield, high stability, and great adaptability simultaneously over crop seasons. Despite the coincidence selection of the three superior full-sib families based on the average among all crop seasons, there were changes in the rank for the other full-sib families due to the significant low correlation between crop seasons and the family $\mathrm{x}$ crop season interaction in a complex way.

Table 4. Stability of genotypic values (HMGV), adaptability of genotypic values (RPGV and RPGVu), stability and adaptability of genotypic values (HMRPGV and HMRPGV $\mu$ ) for grain yield ( $\mathrm{g} /$ plant) evaluated in 13 fullsib families in five crop seasons predicted by BLUP analysis.

\begin{tabular}{l|c|c|c|c|c}
\hline Family & HMGV & RPGV & RPGV $\mu^{*}$ & HMRPGV & HMRPGV $\mu^{*}$ \\
\hline 1 & 74.81 & 1.20 & 630.63 & 1.05 & 551.41 \\
\hline 2 & 18.57 & 1.02 & 536.55 & 0.49 & 257.68 \\
\hline 3 & 84.61 & 0.76 & 399.53 & 0.73 & 387.45 \\
\hline 4 & 191.96 & 1.44 & 761.50 & 1.25 & 660.55 \\
\hline 5 & 55.18 & 0.70 & 367.23 & 0.67 & 352.16 \\
\hline 6 & 151.46 & 1.25 & 658.81 & 1.09 & 572.28 \\
\hline 7 & 161.30 & 1.02 & 538.96 & 0.74 & 391.67 \\
\hline 8 & 78.77 & 1.27 & 671.22 & 1.12 & 592.56 \\
\hline 10 & 123.60 & 1.39 & 731.23 & 1.31 & 691.97 \\
\hline 11 & 88.89 & 0.75 & 397.78 & 0.70 & 368.43 \\
\hline 12 & 33.21 & 0.72 & 382.10 & 0.55 & 291.72 \\
\hline 13 & 49.26 & 0.54 & 282.97 & 0.45 & 236.35 \\
\hline
\end{tabular}

*Values of RPGV $\mu$ and HMRPGV $\mu$ were obtained by multiplying the genotypic value of the yield grain of the genotype $\mathrm{i}$ with the statistics RPGV and HMRPGV, respectively.

The interpretation of the performance of the perennial species over crop seasons is fundamental to help breeders recommend superior genotypes, especially for traits with low heritability such as grain yield (Resende, 2002). Estimates of the phenotypic averages for grain yield were higher in the fourth and fifth crop seasons (Table 5), which took for a positive environmental gradient for these crop seasons, and consequently, they can be considered as favorable environments according to Finlay and Wilkinson (1963) classification. These results are following the literature because according to Bahadur et al. (2012) the maximum productive potential of Jatropha plants is reached 4 or 5 years after planting.

Table 5. Phenotypic mean, environmental gradient, and classification of each season according to Finlay and Wilkinson (1963).

\begin{tabular}{l|c|c|c}
\hline Crop season & Phenotypic mean & Environmental gradient & Classification \\
\hline 1 & 30.23 & -498.06 & Unfavorable \\
\hline 2 & 216.99 & -311.30 & Unfavorable \\
\hline 3 & 293.28 & -235.01 & Unfavorable \\
\hline 4 & 1043.34 & 515.05 & Favorable \\
\hline 5 & 1057.60 & 529.31 & Favorable \\
\hline
\end{tabular}

Figure 1 shows the reaction norm for the three superior families according to the average of GV over crop season and HMRPGV method. Reaction norm represents the genotypic performance of a specific genotype in function of the environmental gradient (Falconer and Mackay, 1996). The outcomes obtained by reaction norm for the 4, 8, and 9 full-sib families were similar than Eberhart and Russell (1966), although the regression coefficients are estimated using the predicted GV for each crop season. Superior families have regression coefficient $(\beta 1)$ greater than 1 , which indicates an increase of GV with the

Genetics and Molecular Research 16 (3): gmr16039722 
environment improvement (Eberhart and Russell, 1966). Moreover, these families have high stability $\left(\mathrm{R}^{2}>0.80\right)$ of genotypic performance over environmental gradients.

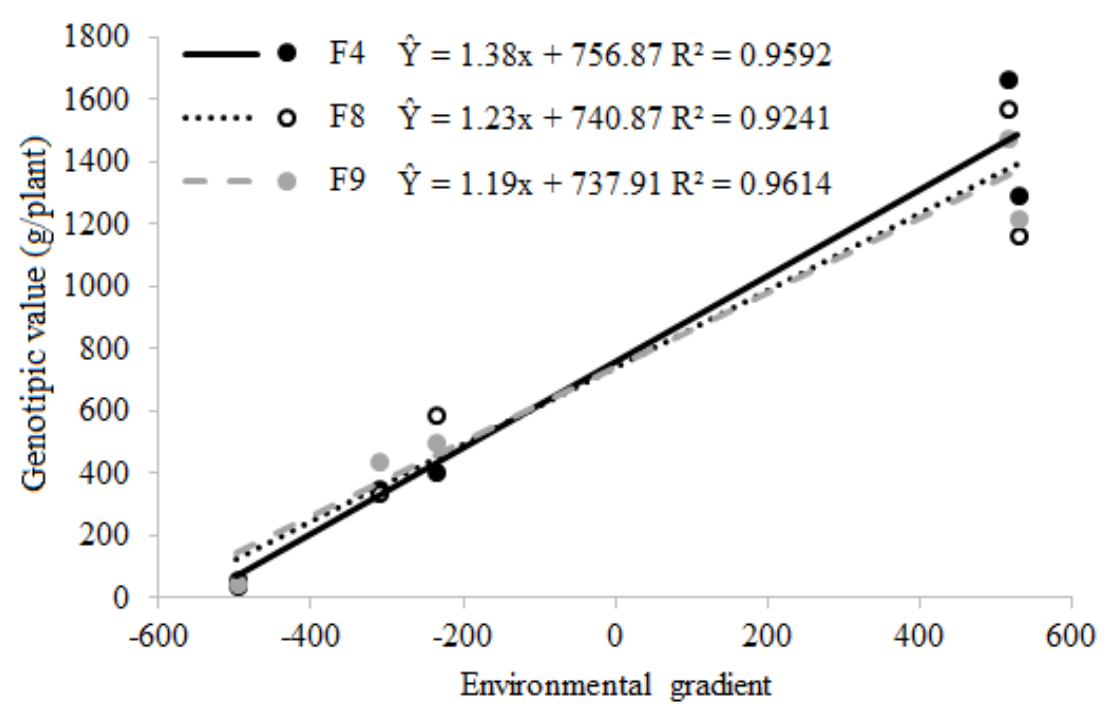

Figure 1. Reaction norms of the three superior families selected by genotypic values and HMRPGV method.

Researchers investigating the effect of genotypic adaptability and stability on Jatropha genotypes are rare (Spinelli et al., 2015; Teodoro et al., 2016), which indicates the importance of this study. The selection of genotypes, which increases their performance with the environmental improvement, is an important factor to increase the grain yield and oilseed yield in Jatropha since these traits have large environmental influence. Therefore, findings reported in this research represent an advance to Jatropha breeding in Brazil and imply the utilization of the superior genotypes selected based on analyses presented for farmers by vegetative propagation.

\section{Selection of superior plants within full-sib families}

Selection of superior plants is fundamental to increase grain yield in perennial species such as Jatropha with the minimum possible costs (Bahadur et al., 2012; Carels et al., 2013). In this study, the last crop season was considered to select superior individual plants within fullsib families since Jatropha has its grain yield stabilized beyond the fifth crop season (Laviola et al., 2013). Moreover, grain yield was highest in the fifth crop season for almost all evaluated full-sib families.

Two criteria were performed aiming to select the 30 superior individual plants based on grain yield: effective population size and selection intensity considering three plants per full-sib family defined by the maximization of the inferior limit of the confidence interval of genotypic value corrected by endogamy coefficient (Resende, 2002). The predicted genetic gain crossing the 30 superior individual plants was $31.05 \%$ (Table 6), that was superior to the estimates of predicted genetic gain performed by Spinelli et al. (2015).

Genetics and Molecular Research 16 (3): gmr16039722 
Table 6. Estimates of additive genotypic values plus the overall mean of grain yield (g/plant) of Jatropha related to 30 plants selected to compose a recombination unit.

\begin{tabular}{|c|c|c|c|c|}
\hline Order & Block & Family & Plant & Aditive genotypic value predicted \\
\hline 1 & 4 & 9 & 3 & 1818.60 \\
\hline 2 & 2 & 9 & 2 & 1600.80 \\
\hline 3 & 3 & 9 & 2 & 1599.49 \\
\hline 4 & 4 & 2 & 3 & 1568.86 \\
\hline 5 & 4 & 8 & 1 & 1509.65 \\
\hline 6 & 2 & 1 & 3 & 1500.47 \\
\hline 7 & 1 & 1 & 1 & 1488.69 \\
\hline 8 & 3 & 6 & 2 & 1480.13 \\
\hline 9 & 4 & 2 & 2 & 1479.60 \\
\hline 10 & 1 & 8 & 2 & 1457.92 \\
\hline 11 & 5 & 5 & 1 & 1418.69 \\
\hline 12 & 2 & 6 & 3 & 1391.63 \\
\hline 13 & 5 & 5 & 2 & 1366.10 \\
\hline 14 & 4 & 2 & 3 & 1360.08 \\
\hline 15 & 5 & 8 & 2 & 1352.54 \\
\hline 16 & 5 & 2 & 2 & 1351.12 \\
\hline 17 & 3 & 1 & 3 & 1342.03 \\
\hline 18 & 3 & 5 & 3 & 1298.70 \\
\hline 19 & 1 & 12 & 2 & 1292.69 \\
\hline 20 & 5 & 4 & 1 & 1267.42 \\
\hline 21 & 5 & 4 & 3 & 1267.42 \\
\hline 22 & 2 & 10 & 2 & 1247.22 \\
\hline 23 & 4 & 10 & 1 & 1228.85 \\
\hline 24 & 1 & 3 & 2 & 1226.21 \\
\hline 25 & 4 & 12 & 3 & 1221.01 \\
\hline 26 & 5 & 10 & 3 & 1220.78 \\
\hline 27 & 5 & 7 & 1 & 1214.83 \\
\hline 28 & 2 & 12 & 3 & 1214.75 \\
\hline 29 & 4 & 4 & 3 & 1212.48 \\
\hline 30 & 4 & 3 & 2 & 1187.51 \\
\hline \multicolumn{4}{|c|}{ Overall mean } & 1047.51 \\
\hline \multicolumn{4}{|c|}{ New mean } & 1372.81 \\
\hline \multicolumn{4}{|c|}{ Selection gain (\%) } & $31.05 \%$ \\
\hline
\end{tabular}

Despite the effective population size considered in this study, other studies demonstrated the needed to insert new access to increase the genetic diversity of the Brazilian Jatropha genotypes (Rosado et al., 2010; Bhering et al., 2013; Bhering et al., 2015).

Moreover, it was observed that the three superior plants belonged to the full-sib family 9, which has high genotypic adaptability and stability. Family 9 was obtained by the selfpollination of the genotype 190 characterized for high grain yield. Therefore, these findings reinforce the possibility to use clones for the family as commercial varieties. Furthermore, individuals belong to families $8,2,1,6$, and 5 may be used for crossing and cloning process.

\section{ACKNOWLEDGMENTS}

We thank CAPES, CNPq, FAPEMIG, FUNARBE, and the Federal University of Viçosa for financial support. We also thank the Biometric Lab (Federal University of Viçosa, Brazil) where all analyses were performed by remote access.

\section{REFERENCES}

Bahadur B, Sujatha M and Carels Np (2012). Jatropha, Challenges for a New Energy Crop: Genetic Improvement and Biotechnology. Springer Science \& Business Media.

Genetics and Molecular Research 16 (3): gmr16039722 
Bhering LL, Barrera CF, Ortega D, Laviola BG, et al. (2013). Differential response of Jatropha genotypes to different selection methods indicates that combined selection is more suited than other methods for rapid improvement of the species. Ind. Crops Prod. 41: 260-265 https://doi.org/10.1016/j.indcrop.2012.04.026.

Bhering LL, de Azevedo Peixoto L, Leite NLSF and Laviola BG (2015). Molecular analysis reveals new strategy for data collection in order to explore variability in Jatropha. Ind. Crops Prod. 74: 898-902 https://doi.org/10.1016/j. indcrop.2015.06.004.

Borges CV, Ferreira FM, Rocha RB, Santos ARd et al. (2014). Capacidade produtiva e progresso genético de pinhãomanso. Cienc. Rural 44: 64-70. https://doi.org/10.1590/S0103-84782014000100011

Carels N, Sujatha M and Bahadur B (2013). Jatropha, Challenges for a New Energy Crop: Farming, Economics and Biofuel. Springer Verlag.

Costa AF, Leal NR, Ventura JA, Gonçalves LSA, et al. (2015). Adaptability and stability of strawberry cultivars using a mixed model. Acta Sci. Agron. 37: 435-440 https://doi.org/10.4025/actasciagron.v37i4.18251.

Eberhart SA and Russell WA (1966). Stability parameters for comparing varieties 1. Crop Sci. 6: 36-40. http://doi:10.2135/ cropsci1966.0011183X000600010011x

Falconer D and Mackay T (1996). Introduction to Quantitative Genetics. Longman Scientific \& Technical, Harlow, UK.

Farias FJ, Carvalho LP, Silva Filho JL and Teodoro PE (2016). Usefulness of the HMRPGV method for simultaneous selection of upland cotton genotypes with greater fiber length and high yield stability. Genet. Mol. Res. 15: 1-8 https:// doi.org/10.4238/gmr.15038439.

Finlay K and Wilkinson G (1963). The analysis of adaptation in a plant-breeding programme. Aust. J. Agric. Res. 14: 742754 https://doi.org/10.1071/AR9630742.

Laviola BG, Rosado TB, Bhering LL, Kobayashi AK, et al. (2010). Genetic parameters and variability in physic nut accessions during early developmental stages. Pes. Agropec. Bras. 45: 1117-1123 https://doi.org/10.1590/S0100204X2010001000010.

Laviola BG, Oliveira AMC, Bhering LL, Alves AA, et al. (2013). Estimates of repeatability coefficients and selection gains in Jatropha indicate that higher cumulative genetic gains can be obtained by relaxing the degree of certainty in predicting the best families. Ind. Crops Prod. 51: 70-76 https://doi.org/10.1016/j.indcrop.2013.08.016.

Montes JM and Melchinger AE (2016). Domestication and breeding of Jatropha curcas L. Trends Plant Sci. 21: 10451057 https://doi.org/10.1016/j.tplants.2016.08.008.

Peixoto LA, Bhering LL and Cruz CD (2016). Determination of the optimal number of markers and individuals in a training population necessary for maximum prediction accuracy in F2 populations by using genomic selection models. Genet. Mol. Res. 15: https://doi.org/10.4238/gmr15048874.

R Core Team (2015). R: A Language and Environment for Statistical Computing. R Foundation for Statistical Computing, Vienna, Austria.

Resende MDV (2002). Genética biométrica e estatística no melhoramento de plantas perenes, Brasília.

Resende MDV (2016). Software Selegen-REML/BLUP: a useful tool for plant breeding. Crop Breed. Appl. Biotechnol. 16: 330-339 https://doi.org/10.1590/1984-70332016v16n4a49.

Resende MDV, Silva FF and Azevedo CF (2014). Estatística Matemática, Biométrica e Computacional: modelos mistos, multivariados, categóricos e generalizados (REML/BLUP), inferência bayesiana, regressão aleatória, seleção genômica, QTL-GWAS, estatística espacial e temporal, competição, sobrevivência. Suprema, Visconde do Rio Branco.

Rosado TB, Laviola BG, Faria DA, Pappas MR, et al. (2010). Molecular markers reveal limited genetic diversity in a large germplasm collection of the biofuel crop L. in Brazil. Crop Sci. 50: 2372. https://doi:10.2135/cropsci2010.02.0112

Sharma S, Dhamija HK and Parashar B (2012). Jatropha curcas: a review. Asian J. Res. Phar. Sci. 2: 107-111.

Silva GAP, Gouvêa LRL, Verardi CK, de Oliveira ALB, et al. (2014). Annual growth increment and stability of rubber yield in the tapping phase in rubber tree clones: Implications for early selection. Ind. Crops Prod. 52: 801-808 https:// doi.org/10.1016/j.indcrop.2013.12.010.

Silva PH, Miranda AC, Moraes ML, Furtado EL et al. (2013). Selecting for rust (Puccinia psidii) resistance in Eucalyptus grandis in São Paulo State, Brazil. For. Ecol. Man. 303: 91-97. https://doi.org/10.1016/j.foreco.2013.04.002

Silva Junqueira V, Azevedo Peixoto Ld, Galvêas Laviola B, Lopes Bhering L, et al. (2016). Bayesian multi-trait analysis reveals a useful tool to increase oil concentration and to decrease toxicity in Jatropha curcas L. PLoS One 11: e0157038 https://doi.org/10.1371/journal.pone.0157038.

Spinelli VM, Dias LAS, Rocha RB and Resende MDV (2015). Estimates of genetic parameters with selection within and between half-sib families of Jatropha curcas L. Ind. Crops Prod. 69: 355-361 https://doi.org/10.1016/j. indcrop.2015.02.024.

Teodoro PE, Bhering LL, Costa RD, Rocha RB, et al. (2016). Mixed models for selection of Jatropha progenies with high adaptability and yield stability in Brazilian regions. Genet. Mol. Res. 15: https://doi.org/10.4238/gmr.15038824.

Genetics and Molecular Research 16 (3): gmr16039722 